\title{
The Effect of Target Group Size on Risk Judgments and Comparative Optimism: The More, the Riskier
}

\author{
Paul C. Price and Andrew R. Smith California State University, Fresno \\ Heather C. Lench University of California, Irvine
}

\begin{abstract}
In 5 experiments, college students exhibited a group size effect on risk judgments. As the number of individuals in a target group increased, so did participants' judgments of the risk of the average member of the group for a variety of negative life events. This happened regardless of whether the stimuli consisted of photographs of real peers or stick-figure representations of peers. As a result, the degree to which participants exhibited comparative optimism (i.e., judged themselves to be at lower risk than their peers) also increased as the size of the comparison group increased. These results suggest that the typical comparative optimism effect reported so often in the literature might be, at least in part, a group size effect. Additional results include a group size effect on judgments of the likelihood that the average group member will experience positive and neutral events and a group size effect on perceptual judgments of the heights of stick figures. These latter results, in particular, support the existence of a simple, general cognitive mechanism that integrates stimulus numerosity into quantitative judgments about that stimulus.
\end{abstract}

Keywords: social cognition, comparative optimism, risk perception, probability judgment, numerosity perception

People have a strong tendency to judge themselves to be at lower risk than their peers for a wide variety of negative events such as developing heart disease, being injured in a car crash, and getting a divorce (e.g., Helweg-Larsen \& Sheppard, 2001; Perloff \& Fetzer, 1986; Price, Pentecost, \& Voth, 2002; Weinstein, 1980, 1987, 1989). We refer to this as comparative optimism. ${ }^{1}$ Although there is a sense in which this phenomenon is intuitive-nonpsychologists seem quite familiar with this kind of irrational, "It won't happen to me" response-it has been surprisingly tricky for social and cognitive psychologists to explain satisfactorily (Weinstein \& Klein, 1996). With the present research, we hope to add an important piece to this puzzle.

Our proposal is that risk judgments about the average or typical member of a target group tend to increase as a continuous, roughly logarithmic function of the size of that group. In general, an individual is judged to be at lower risk than the average or typical member of a group of two, who in turn is judged to be at lower risk than the average or typical member of a group of three, and so on. Furthermore, we propose that this group size effect is the result of a simple, general cognitive mechanism that integrates the number

Paul C. Price and Andrew R. Smith, Department of Psychology, California State University, Fresno; Heather C. Lench, Department of Psychology and Social Behavior, University of California, Irvine.

This research was supported in part by a grant from the Program in Decision, Risk, and Management Science, National Science Foundation. We thank Paul Slovic for suggesting the general affective theory presented here. We also thank Sierra White, Cesar Anaya, Jenn Soares, and the other members of the Social and Health Cognition Lab at CSU Fresno for their help throughout this project.

This article may not exactly replicate the final version published in the APA journal. It is not the copy of record. of distinct elements in a stimulus into quantitative judgments about that stimulus (Pelham, Sumarta, \& Myaskovsky, 1994). Under some conditions, this group size effect is enough to account for the typical comparative optimism effect because a risk judgment about oneself is a judgment about a small group and should, therefore, be relatively low, whereas a risk judgment about one's average peer is a judgment about a large group and should, therefore, be relatively high. It is also consistent with the fact that individuals other than the self are judged to be at lower risk than their peers (e.g., Perloff \& Fetzer, 1986), and it suggests a surprising reason (see Experiment 3) why comparative optimism for positive events tends to be weaker and less reliable than comparative optimism for negative events (e.g., Weinstein, 1980). The group size effect is also interesting because there is reason to believe that it extends

\footnotetext{
${ }^{1}$ We prefer the term comparative optimism to a number of synonyms that have appeared in the literature, including unrealistic optimism (e.g., Weinstein, 1980) and optimistic bias (e.g., Weinstein, 1989) All three terms refer to people judging their risk of experiencing negative life events to be lower than that of their peers and sometimes to people judging their likelihood of experiencing positive life events to be higher than that of their peers (Hoorens, 1996). One reason to prefer comparative optimism, however, is that the others cannot be applied at the level of the individual participant. An individual who judges him- or herself to be at lower than average risk cannot usually be said to be unrealistic or biased because the individual's objective risk is usually not measured (Weinstein \& Klein, 1996). A second reason is that unrealistic optimism, in particular, implies that people believe that they are at particularly low risk. In fact, in many cases, people judge their own risk accurately but overestimate their peers' risk (e.g., Rothman, Klein, \& Weinstein, 1996). The term comparative optimism seems to describe the empirical phenomenon without implying that individuals are incorrect in judging their own risk to be lower than that of their peers or that they are underestimating their own risk as opposed to overestimating their peers' risk.
} 
well beyond the domain of risk judgment (see especially Experiment 5) and that it has important implications for social judgment more generally.

In the rest of this study, we review our initial work on the group size effect on memory-based judgments of heart attack risk. We then consider some alternative explanations of this phenomenon before presenting a series of experiments that replicate the group size effect for a variety of online risk judgments and a variety of negative events. In this empirical work, we also introduce several manipulations and methodological variations that help distinguish among the competing theories of the group size effect. Ultimately, we return to the issue of the group size effect's role in comparative optimism and in social judgment more generally.

\section{The Group Size Effect}

Price (2001) originally hypothesized that risk judgments are subject to a group size effect. He noted that previous research had shown that when people make risk judgments about themselves and about another specific individual, as opposed to their average peer, the magnitude of comparative optimism is greatly reduced. For example, Perloff and Fetzer (1986) found that college students judged their own risk to be lower than that of the average college student and the average person but roughly the same as that of their closest friend, same-sex parent, and a sibling (for similar results, see also Alicke, Klotz, Breitenbecher, Yurak, \& Vredenburg, 1995; Harris \& Middleton, 1994; Klar, Medding, \& Sarel, 1996; Regan, Snyder, \& Kassin, 1995; see Hoorens \& Buunk, 1993, for a null result). Price also noted limited evidence that risk judgments increase as a continuous function of target group size. Specifically, Whitley and Hern (1991) found that college women judged the pregnancy risk of their best friend to be about the same as their own, the pregnancy risk of the average college woman to be greater, and the pregnancy risk of the average woman to be greater still (see also Burger \& Burns, 1988). None of these results had previously been interpreted as an effect of group size per se. Instead, they were interpreted as indicating differences in how people think about individuals versus groups (Klar et al., 1996), specific versus generalized targets (e.g., Alicke et al., 1995), or targets that are more or less similar to themselves (e.g., Whitley \& Hern, 1991).

To demonstrate a true group size effect and to rule out alternative interpretations of it, Price (2001) abandoned the correlational approach typically used in research on comparative optimism in favor of an experimental paradigm adapted from research on category learning and frequency judgment. Participants read a series of heart attack risk profiles for individual employees at different fictional businesses. These risk profiles were simple descriptions of the employees in terms of eight binary risk factors for having a heart attack (e.g., blood pressure: high vs. low). This allowed for the manipulation of both group size (number of employees at a business) and objective risk of the average group member (average number of high-risk features), and also for the control of potential confounding variables. He found that participants' risk judgments were sensitive to the objective risk of the individuals but also that the judged risk of the typical employee increased as a function of group size regardless of the objective risk. For example, in one experiment, participants judged the risk of the typical employee to be greater as the number of employees increased from one to five to nine but in a negatively accelerated way. Although participants in these experiments did not judge their own risk of having a heart attack, the implications of the group size effect for comparative optimism are straightforward. Because the self is a very small group, it should tend to be judged at lower risk than the average peer (a very large group), independently of motivated or nonmotivated differences in how people think about themselves versus their peers.

\section{Possible Explanations of the Group Size Effect}

Price (2001) originally suggested that the group size effect might be a cognitive phenomenon that depends on how people attend to, store, retrieve, and integrate information, and he presented a quantitative model based on Fiedler's (1996) Brunswikian Induction Algorithm for Social Cognition (BIAS) framework for understanding social judgment. This model featured the following assumptions. (a) People encode in memory each individual in terms of that individual's risk factors, although with a certain amount of random error; (b) they are especially likely to encode high-risk features (e.g., high blood pressure); (c) at the time of judgment, they mentally average their representations of the individuals; and (d) their judgment is based on the match between their mental average and the prototype of a high-risk individual. The important implication of this model is that the mental average comes to match the high-risk prototype more closely as the number of individuals increases. This is because of both the selective encoding of high-risk features and the canceling of random error with increasing group size (see Price, 2001, for details). Alternatively, Price suggested that people might base their risk judgments in part on the judged frequency of high-risk individuals or highrisk features in the group. We refer to these three cognitive explanations as the BIAS theory, the high-risk individual theory, and the high-risk feature theory.

Another kind of cognitive explanation, not originally considered by Price (2001), is that people base their risk judgments in part on the total number of individuals in the group. This is consistent with two different lines of research. First, Pelham et al. (1994) have argued that people often use a numerosity heuristic to make quantitative judgments. That is, they use the number of distinct elements in a stimulus as a cue to judging other quantitative dimensions of that stimulus. Although this makes sense in many situations (e.g., the number of slices of pizza on the table is a good indicator of the total amount of pizza), it can sometimes be misleading. For example, Pelham et al. (1994) found that people estimated the area of a circle to be greater when it was divided into eight separate wedges than when it was presented intact and to estimate the sum of eight small numbers to be greater than the sum of four larger numbers when, in fact, the two sums were the same. It seems plausible, therefore, that people might use the number of people in a group as a cue to judging the risk of the average group member. Second, Wilson, Houston, Etling, and Brekke (1996) have demonstrated a phenomenon they call basic anchoring, in which an irrelevant number is integrated with a quantitative judgment made shortly after processing that irrelevant number. For example, in one study, participants' judgments of the number of physicians listed in the local telephone book were influenced by an identification number that they had previously been assigned and asked to think minimally about. It seems plausible that the number 
of individuals in a group might serve as a kind of basic anchor, which is integrated with people's risk judgments. We return to consider these processes in more detail in the General Discussion. For now, however, we refer to the general idea that people's judgments are influenced by the total number of individuals as the numerosity theory.

Another kind of explanation for the group size effect is based on affective approaches to understanding risk perception (Finucane, Alhakami, Slovic, \& Johnson, 2000; Loewenstein, Weber, Hsee, \& Welch, 2001; Slovic, Finucane, Peters, \& MacGregor, 2002). It is well known that people can have quick, automatic, even unconscious affective reactions to a variety of stimuli (Zajonc, 2000). It is also well known that such affective reactions can influence a wide range of evaluative judgments about those stimuli (e.g., Schwarz, 1990; Zajonc, 2000). It is possible, then, that people have a negative affective reaction to thinking about other people's risk for negative events and that this negative affective reaction is reflected in high risk judgments. If we assume further that the strength of this negative affective reaction increases as a function of group size, then the group size effect follows. Why would the strength of the negative affective reaction increase as a function of group size? One possibility is that people accurately perceive that the absolute number of individuals in the group to whom the event will happen increases as a function of group size. For example, people might reasonably assume that a certain individual will not have a heart attack and, therefore, not experience much of a negative affective reaction. However, when considering a group of 10 , people might reasonably assume that they are considering a minimum of three or four future heart attack victims, producing a stronger negative affective reaction. Another possibility is that people have an affective reaction that is proportional to the number of high-risk features or high-risk individuals that they perceive in the group as a whole. We refer to this general category of explanation as the affective theory.

A final explanation is that the group size effect is an example (or perhaps generalization) of the person-positivity bias in evaluative social judgment. Sears (1983) observed that individuals tend to be evaluated more positively than the groups to which they belong. He proposed that this is because people perceive themselves to be more similar to individuals than to groups, which in turn results in their liking individuals more than groups (see also Miller \& Felicio, 1990; see Nilsson \& Ekehammar, 1987, for a null result). It is this difference in liking that causes them to evaluate individuals more positively than groups. Given these assumptions, it seems plausible that people might perceive the average member of a larger group to be less similar to themselves, like that comparison target less, and therefore judge that comparison target to be at greater risk (see also Hoorens \& Buunk, 1993; Regan et al., 1995).

\section{Indirect Versus Direct Comparative Judgments}

Before proceeding, we should discuss an important methodological issue, partly for the sake of clarity but also because, as we have noted elsewhere (Price et al., 2002), this particular methodological detail can have a major impact on the empirical and theoretical conclusions one draws about comparative optimism.

As many researchers have noted, comparative optimism is fairly robust across two basic measurement methods (Klar et al., 1996; Otten \& Van der Pligt, 1996; Price et al., 2002; Weinstein \& Klein,
1996). In the indirect method, participants make two separate risk judgments: one for themselves and one for their peers. The researchers then take the difference between the two judgments, generally finding that the self-risk judgments are considerably lower than the peer-risk judgments. (It would also make sense for the researchers to take the ratio of the two judgments, but this is not typically done; Klar \& Ayal, 2004.) This difference can be taken either between subjects or, more commonly, within subjects. Not surprisingly, the within-subjects effect is generally stronger (Otten \& Van der Pligt, 1996). In the direct method, participants make a single judgment of their own risk relative to that of their peers. For example, they might judge their risk on a 7-point numerical scale, with 4 said to represent their average peer's risk. These judgments are generally lower than 4 (or whatever response is specified as the peers' risk), again indicating comparative optimism.

In the present research, we focus on the indirect method rather than the direct method. This is because the group size effect hypothesis most clearly implies an effect on comparative optimism using this method. The difference between participants' peer-risk and self-risk judgments should increase as a function of comparison group size because their peer-risk judgments should increase and their self-risk judgments should remain constant (and relatively low). There are also theoretical reasons to believe that the direct method might produce a weaker or even null group size effect. Specifically, a number of researchers have suggested that, in making direct comparative judgments, people pay relatively little attention to the comparison group (Eiser, Pahl, \& Prins, 2001; Klar \& Giladi, 1997, 1999; Kruger, 1999; Price et al., 2002). For now, we leave open the possibility that indirect and direct comparative judgments might be affected differently by group size, although we included a direct condition in one experiment (Experiment 2) and found strong initial evidence for a group size effect even there.

\section{The Present Experiments}

We conducted the present experiments with three major goals in mind. The first was to replicate the group size effect using different stimuli (e.g., photographs of people rather than written feature lists), different negative life events, and different measurement methods from those of Price (2001). Our second goal was to show more conclusively that group size can be a contributor to comparative optimism, and how big a contributor it is, by asking participants to judge their own risk in addition to or compared with that of the average member of groups of different sizes. An interesting question is whether people judge themselves to be at lower risk than other individuals or whether comparative optimism is observed only when the comparison target is a group. The results of previous research on this particular question have been somewhat ambiguous (Harris \& Middleton, 1994; Hoorens \& Buunk, 1993; Klar et al., 1996; Regan et al., 1995). Note that the presence of a comparative optimism effect when the comparison target is another individual would imply that comparative optimism cannot be entirely reduced to a group size effect. Our third goal was to evaluate potential explanations of the group size effect by varying our experimental design and procedure in several ways that are explained in the relevant Method sections. 


\section{Experiment 1}

The primary goal of Experiment 1 was to replicate the group size effect demonstrated by Price (2001) using a wider variety of negative events (not just having a heart attack) and, more importantly, using photographs of people as stimuli (rather than written descriptions). Specifically, participants saw photographs of groups of $1,5,10$, and 15 peers and judged the risk that various negative events would happen to the average group member. We hypothesized that risk judgments would increase as a function of target group size. We also asked participants to judge their own risk for the same negative life events so that we could (a) determine whether they judge themselves to be at lower risk than other stimulus individuals and (b) show definitively that comparative optimism, measured by the indirect method, increases as a function of comparison group size.

Note that this experiment has theoretical implications too, especially for explanations that emphasize selective memory for high-risk features or high-risk individuals, including the BIAS theory. Such explanations suggest that the experimental procedure of Price (2001) would be particularly likely to produce a group size effect. One reason is that the encoding and retrieval of stimulus individuals in terms of specific risk factors would be encouraged, if not demanded, by the fact that the individual employees were described by lists of specific risk factors. A second reason is that the risk judgments were memory based, so that the selective encoding and retrieval of high-risk information would be likely to affect them. In contrast, in this experiment (and all the others presented here), the risk judgments were made online, with all high-risk and low-risk stimulus information equally available at the time of judgment. Also, this information was not conveniently presented as lists of risk factors. We believe that a group size effect under such conditions would provide evidence against explanations that rely on selective memory.

\section{Method}

Participants. The participants were 60 undergraduate students at California State University, Fresno (CSUF). They participated as part of an introductory psychology course requirement.

Stimuli. We took digital photographs of 30 different young adults, including advanced psychology students at CSUF and nonstudent friends and acquaintances of the experimenters. There were 16 women and 14 men, who were at least somewhat representative of the racial diversity of CSUF students and the local community. Each photograph featured the individual in his or her everyday clothing, standing informally and facing forward. We digitally removed the backgrounds from the photographs and printed them onto standard overhead transparencies for presentation. Specifically, we divided the photographs into two groups of 15 individuals and printed each group, organized into three rows of five, onto a transparency. We also divided each group of 15 into separate groups of 5 and 10 (individuals in the first row vs. those in the second and third rows) and printed them onto separate transparencies. Finally, we printed a photograph of each of the 30 individuals onto a separate transparency. This allowed us to use a standard overhead projector to present our participants with the 30 individuals separately, along with the same 30 individuals organized into mutually exclusive groups of 5,10 , and 15 . Furthermore, we could present two different groupings of the 30 individuals into groups of 5, 10, and 15 to help control for the effects of how specific stimulus individuals were assigned to groups.

Design and procedure. Participants were tested in noninteracting groups of 5 to $10 \mathrm{in} \mathrm{a} \mathrm{classroom} \mathrm{on} \mathrm{the} \mathrm{university} \mathrm{campus.} \mathrm{Half} \mathrm{of} \mathrm{these}$ groups were randomly assigned to the groups-first condition and the rest to the groups-last condition. In the groups-first condition $(n=35)$, participants judged the risk of the average member of the groups of 5,10 , and 15 for each of four events (developing cancer, being injured in a car crash, breaking a bone, and becoming alcoholic), and then they judged the risk of each of the individuals for the same four events. In the groups-last condition $(n=25)$, they judged the risk of each of the 30 individuals first and then they judged the risk of the average member of the groups of 5,10 , and 15. Within each session, both the individuals and the groups of 5, 10, and 15 were presented in different randomized orders. Also, each of the two alternative groupings of the 30 individuals was used for roughly half the sessions.

Participants made their risk judgments using a 101-point numerical risk scale $(0=$ lowest possible risk, $50=$ moderate risk, $100=$ highest possible risk). Participants sat at classroom desks positioned roughly 5 to $7 \mathrm{~m}$ from a projection screen, and an overhead projector displayed the stimulus images on the screen. The images were large and clear enough for participants to see easily, including specific features of the individuals that might be relevant to their risk judgments (e.g., sex of the person, style of dress) Each individual or group was presented for however long it took all participants to make all four risk judgments, usually not more than $30 \mathrm{~s}$. They wrote their risk judgments on a separate response sheet. After making all of their peer-risk judgments, participants completed a self-risk questionnaire, again using the 101-point numerical risk scale, for the same four events.

\section{Results and Discussion}

For each participant, we computed the mean risk judgment across the 30 individuals and four events to arrive at a mean individual peer-risk judgment. Also, for each participant, we computed the mean risk judgment for the groups of 5, 10, and 15 across the four events to arrive at three mean group-risk judgments. Figure 1 presents the means of these four mean risk judgments as a function of the logarithm of the group size, separately for participants in the groups-first and groups-last conditions. (Stan-

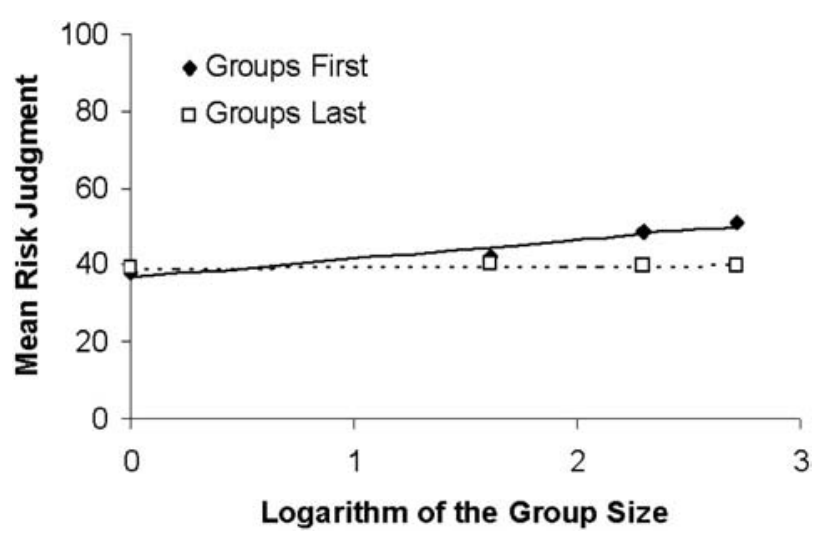

Figure 1. Mean peer-risk judgments as a function of the logarithm of the group size for Experiment 1, both when the stimulus groups preceded the individuals (the groups-first condition) and vice versa (the groups-last condition). Each regression line can be interpreted either as the line that best fits the four means or as the line defined by the mean regression coefficient and the mean regression constant taken across participants in that condition. The stimuli were photographs of real peers. The risk judgments were made on a scale ranging from 0 to 100 . 
dard deviations for all experiments appear in Table $1 .^{2}$ ) It appears from Figure 1 that there was a group size effect for participants in the groups-first condition but little or no effect for participants in the groups-last condition.

We wanted to analyze these results further within a regression framework to emphasize the roughly log-linear form of the group size effect. To do so, we used a procedure suggested by Lorch and Myers (1990) for repeated measures experimental designs. Specifically, we regressed each participant's four mean risk judgments (for individuals and for groups of 5,10, and 15) onto the logarithm of the group size, obtaining a regression coefficient for each participant. A positive regression coefficient indicates a group size effect, and the consistency of these coefficients across participants indicates the reliability of the effect. We found that the mean regression coefficient $(M=2.92, S D=4.28)$ was significantly greater than 0 , indicating an overall group size effect, $t(59)=5.29$, $p<.05$. However, the mean regression coefficient in the groups-

Table 1

Standard Deviations of Judgments in Experiments 1 through 5

\begin{tabular}{|c|c|c|c|c|c|c|c|}
\hline \multirow[b]{2}{*}{ Condition/judgment } & \multicolumn{7}{|c|}{ Comparison group size } \\
\hline & 1 & 4 & 5 & 8 & 10 & 12 & 15 \\
\hline \multicolumn{8}{|c|}{ Experiment $1^{\mathrm{a}}$} \\
\hline Groups first & 14.29 & & 15.34 & & 14.05 & & 15.76 \\
\hline Groups last & 12.53 & & 15.66 & & 16.21 & & 14.47 \\
\hline \multicolumn{8}{|c|}{ Experiment 2} \\
\hline Indirect/peer ${ }^{\mathrm{b}}$ & 0.96 & 1.01 & & 1.12 & & 1.09 & \\
\hline Direct ${ }^{\mathrm{c}}$ & 0.72 & 0.76 & & 0.84 & & 0.88 & \\
\hline
\end{tabular}

Experiment 3

\begin{tabular}{|c|c|c|c|c|}
\hline \multicolumn{5}{|c|}{ Negative events } \\
\hline Risk $^{\mathrm{b}}$ & 0.59 & 0.96 & 0.79 & 0.90 \\
\hline Sim. $^{\mathrm{d}}$ & 0.81 & 1.31 & 1.21 & 1.28 \\
\hline \multicolumn{5}{|c|}{ Positive events } \\
\hline Risk $^{\mathrm{b}}$ & 0.61 & 1.03 & 0.88 & 0.92 \\
\hline Sim. $^{\text {d }}$ & 0.85 & 1.46 & 1.22 & 1.00 \\
\hline \multicolumn{5}{|c|}{ Neutral events } \\
\hline Risk $^{\mathrm{b}}$ & 0.57 & 0.96 & 0.90 & 0.94 \\
\hline Sim. $^{d}$ & 0.94 & 1.44 & 1.48 & 1.38 \\
\hline
\end{tabular}

Experiment $4^{\mathrm{e}}$

\begin{tabular}{llllll} 
Peer risk & 1.55 & 1.26 & 1.48 & 1.45 \\
\hline \multirow{5}{*}{ Experiment $5^{\mathrm{f}}$} \\
Height & 9.09 & 7.58 & 6.51 & 6.86 \\
\hline
\end{tabular}

Note. All risk and likelihood judgments were averaged across multiple events and, when the group size was 1 , across multiple comparison targets. The comparison group sizes differed across the six experiments, accounting for the missing cells in the table. The standard deviations of the self-judgments are presented in the text. Sim. = similarity.

${ }^{a}$ Risk judgments were made on a 101-point numerical scale. ${ }^{\mathrm{b}}$ Risk and likelihood judgments were made on a 7-point verbal scale. ${ }^{\mathrm{c}}$ Direct comparative risk judgments were made on a 7-point verbal scale, with 4 representing the risk of the average comparison group member. ${ }^{\mathrm{d}}$ Similarity judgments were made on a 6-point verbal similarity scale. ${ }^{\mathrm{e}}$ Risk

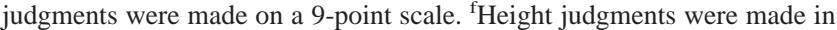
scale feet and inches and converted to scale inches. first condition $(M=4.80, S D=4.65)$ was significantly greater than the mean regression coefficient in the groups-last condition $(M=0.29, S D=1.43), t(58)=4.69, p<.05$, the latter of which was not significantly different from $0, t(24)=1.02, n s$. This entire pattern of significant and nonsignificant results was replicated when we reanalyzed the data excluding the individual peer judgments, showing that this is a group size effect rather than an effect of whether the comparison target is an individual versus a group.

One potential explanation for the order effect is that, in making their risk judgments about the groups, participants in the groupslast condition recalled the risk judgments that they had already made about the individuals. This may have changed their strategy from one of forming a holistic impression of the risk of the average person in the group to one of mentally averaging the numerical risk ratings that they had already made. Because people have been shown to be fairly unbiased at estimating the mean of a series of numbers (Peterson \& Beach, 1967), this strategy would not be expected to produce a group size effect. Alternatively, this could be a mental set effect, in which participants simply continue making judgments that are much like the large number of judgments they have already made. Support for these interpretations comes from the fact that participants in both conditions produced relatively low individual peer-risk judgments and that in the groups-last condition they produced similarly low group-risk judgments.

Finally, participants judged themselves $(M=33.16, S D=$ 17.30) to be at lower risk than even their individual peers, $t(56)=$ 3.35, $p<.05 .^{3}$ Because participants' peer-risk judgments increased as a function of comparison group size, we can also say that comparative optimism increased as a function of comparison group size, at least in the groups-first condition.

\section{Experiment 2}

Both the studies of Price (2001) and Experiment 1 here have demonstrated that group size affects absolute peer-risk judgments and, therefore, comparative optimism using the indirect method. As described previously, however, there is another common way of measuring comparative optimism: the direct method (Klar et al., 1996; Price et al., 2002; Weinstein \& Klein, 1996). In the direct method, participants make a single comparative risk judgment rather than two absolute risk judgments. For example, they might judge their own risk compared with that of their average peer on a 7-point scale, where 4 is said to be the risk of their average peer. A mean rating lower than 4 across a group of participants, therefore, indicates comparative optimism.

However, would the group size effect contribute to comparative optimism measured by the direct method? There is reason to believe that it might not. Specifically, many researchers have argued that direct comparative judgments are based almost exclusively on what people think about themselves. This might be why, for example, people judge themselves to be friendlier than average.

\footnotetext{
${ }^{2}$ We have chosen to present the standard deviations for all five experiments in a single table rather than as error bars in the figures because this makes the figures much easier to read.

${ }^{3}$ Three participants were not included in this analysis because they failed to make self-risk judgments.
} 
Most people are friendly and, therefore, judge themselves to be relatively friendly without considering the fact that, again, most people are friendly (Klar, 2002; Klar \& Giladi, 1997, 1999). This may also be why people judge themselves to be better than average at easy tasks (e.g., riding a bicycle) but worse than average at difficult tasks (e.g., juggling). Most people are good at riding a bicycle, so they judge themselves to be relatively good, and most people are bad at juggling, so they judge themselves to be relatively bad. In both cases, they fail to consider the fact that their peers tend to be about as good or bad as themselves (Kruger, 1999). Price et al. (2002) have applied this argument to risk judgments after showing that people's absolute self-risk judgments are almost perfect predictors of their direct comparative risk judgments; their absolute peer-risk judgments account for very little additional variance (see also Eiser et al., 2001). All of this implies that direct comparative risk judgments might not be subject to the group size effect. If people do not consider their peers when making direct comparative judgments, then the number of peers that constitute the comparison group should not matter. If this were true, then the group size effect would not contribute to comparative optimism measured using the direct method.

For this reason, we conducted Experiment 2 with two conditions. The indirect condition was essentially a replication of Experiment 1, although we intermixed trials on which individuals were presented and trials on which groups were presented so that order was not an issue. In the direct condition, participants judged their own risk compared with that of the comparison target. Again, if people generally disregard the comparison target when making direct comparative judgments, then the direct condition should fail to reveal a group size effect.

\section{Method}

Participants. The participants were 156 undergraduate students at the University of California, Irvine. They participated as part of an introductory psychology course requirement.

Stimuli. We used 28 of the 30 photographs used in Experiment 1 (14 women and $14 \mathrm{men}$ ), organizing them into seven matched sets of 4 (each containing 2 men and 2 women). The matching variable was the mean risk judgment across three events (breaking a bone, developing cancer, and becoming alcoholic) assigned to the stimulus individuals by participants in Experiment 1 . We randomly chose one set of 4 to serve as stimulus individuals (i.e., 4 separate groups of 1), one set to serve as a group of 4 , two sets combined to serve as a group of 8 , and the remaining sets combined to serve as a group of 12 . This constituted Photo Grouping A. We then recombined the seven sets of 4 to obtain Photo Grouping B. For example, the set that served as the 4 stimulus individuals in Grouping A was part of the group of 12 in Grouping B. This allowed us to present each participant with photographs of 4 stimulus individuals, a group of 4 , a group of 8 , and a group of 12 in one of two different ways and such that the groups were roughly matched on the overall perceived risk of the individuals in the groups.

Design and procedure. The design and procedure were similar to those of Experiment 1, but we varied them in a few ways. First, we used only three negative events: breaking a bone, developing cancer, and becoming alcoholic. Second, participants made 21 risk judgments, each on a separate trial. On each trial, we presented participants with one photograph and asked them to make a risk judgment about one event. We established a basic order for the 21 trials, in which each of the seven stimulus photographs (4 individuals, a group of 4 , a group of 8 , and a group of 12) was presented once within each of the first, second, and third blocks of seven trials. Within each block, photographs of individuals and groups were alternated, but the exact order differed from block to block. The event in question also changed from trial to trial, with no event appearing more than three times in a block, and in such a way that each of the seven stimulus photographs was paired once with each of the three events. Of course, we varied which photo grouping (A or B) that we used from session to session, but we also varied the basic order of the trials by reversing it for participants in roughly half the sessions.

The most important difference from Experiment 1, however, was that participants in half the sessions were assigned to the indirect condition and the rest to the direct condition. Participants in the indirect condition $(n=$ 78) judged the risk, on each trial, that the target would experience the event in question. For each stimulus photograph, an experimenter read the risk question aloud (e.g., "What is the risk of [this student/the average student in this group] for becoming alcoholic?"), and participants marked their judgments on a separate response sheet. After making the 21 peer-risk judgments, participants then judged their own risk for each of the three events. The response scale for both the peer-risk and self-risk judgments was a 7-point verbal risk scale: extremely low (1), somewhat low (2), slightly low (3), moderate (4), slightly high (5), somewhat high (6), extremely high (7). Participants in the direct condition $(n=78)$ judged their own risk, on each trial, compared with that of the comparison target for the event in question. Again, for each stimulus photograph, an experimenter read the risk question aloud (e.g., "Compared with the risk of [this student/the average student in this group], what is your risk for becoming alcoholic?"), and participants marked their judgments on a separate response sheet. The response scale was a 7-point verbal scale ranging from much lower risk (1) to much higher risk (7). The midpoint of the scale was same as [this student/the average student in this group] (4).

\section{Results and Discussion}

Indirect condition. For each participant in the indirect condition, we computed the mean individual peer-risk judgment across the four individuals and three events, and we computed the mean group-risk judgment for the 4-, 8-, and 12-member groups across the three events. Figure 2 presents the means of these four mean risk judgments as a function of the logarithm of the group size. Again, we regressed the four mean risk judgments onto the logarithm of the group size, obtaining a regression coefficient for each participant. The mean regression coefficient $(M=0.35, S D=$ 0.47) was significantly greater than $0, t(77)=6.59, p<.05$, indicating a group size effect, which remained even when the individual peer-risk judgments were excluded from the analysis.

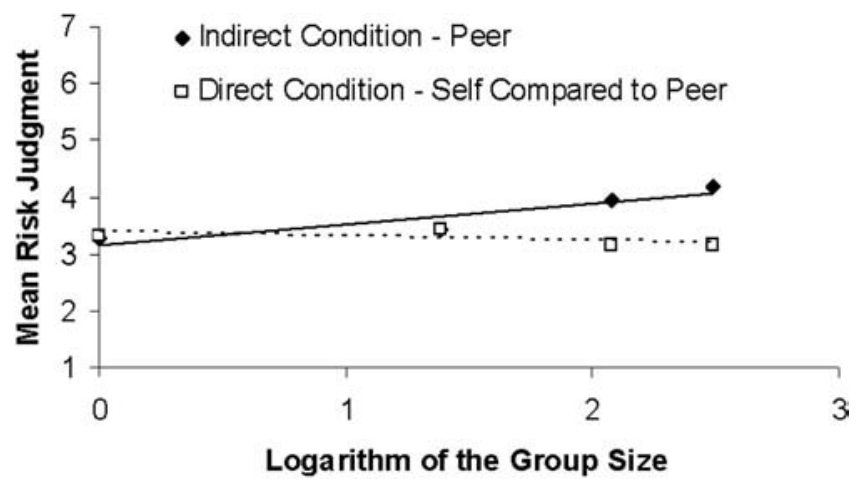

Figure 2. Mean peer-risk judgments (indirect condition) and comparative risk judgments (direct condition) as a function of the logarithm of the group size for Experiment 2. The stimuli were photographs of real peers. Both types of judgment were made on a 7-point verbal scale. 
Note that the mean regression coefficient is much lower here than in Experiment 1 because the response scale ranged from 1 to 7 rather than 0 to 100 . In both cases, however, the mean was more than half a standard deviation above 0 , so the effects were commensurate. Also as in Experiment 1, the group size effect did not completely account for comparative optimism because participants' judged themselves to be at lower risk $(M=2.89, S D=$ 0.89 ) than other individuals, $t(77)=3.36, p<.05$. This means that, as the group size increased, so did the discrepancy between participants' self-risk and peer-risk judgments: their level of comparative optimism.

Direct condition. For each participant in the direct condition, we computed the mean comparative risk judgment across the three events when the comparison target was an individual and when the comparison target was a group of 4,8 , and 12. Figure 2 also presents the means of these four mean comparative risk judgments. Note that these judgments decrease as a roughly linear function of the logarithm of the group size. In other words, as the comparison group increased in size, participants judged their own risk to be farther below that of the average member of the comparison group. This is exactly what the existence of the group size effect would lead us to expect. The average member of a larger group appears to be at greater risk, so people judge their own risk to be farther below that standard.

Again, for each participant, we regressed the four mean comparative risk judgments onto the logarithm of the group size, obtaining a regression coefficient for each participant. The mean regression coefficient was significantly less than $0(M=-0.09$, $S D=0.25)$, confirming that there was a group size effect, $t(77)=$ $3.18, p<.05$. The effect remained when the judgments individual peer-risk were excluded from the analysis. As usual, even though group size contributed to comparative optimism, it did not completely account for it. Even when the comparison target was another individual, participants' comparative risk judgments $(M=$ $3.32, S D=0.72$ ) were significantly lower than $4, t(77)=8.37$, $p<.05$.

The existence of a group size effect in the direct condition is interesting for several reasons. First, it suggests that comparative optimism measured by the direct method, as well as comparative optimism measured by the indirect method, might generally reflect an effect of group size. Second, although the effect of group size on absolute peer-risk judgments is to increase them, the effect on direct comparative judgments is to decrease them (i.e., to move them further below the midpoint of the scale). This shows that the group size effect does not involve a simple translation of more group members into higher judgments. Instead, group size seems to affect people's subjective impression of the risk of the average comparison group member, which in turn becomes input into the direct comparative judgment process. Finally, these results are only partly consistent with theorizing on the difference between indirect and direct comparative judgments (Eiser et al., 2001; Klar, 2002; Klar \& Giladi, 1997, 1999; Kruger, 1999; Price et al., 2002). It is clearly not the case that participants completely disregarded the comparison target in making direct comparative risk judgments, because they were influenced by the size of the comparison group. In contrast, the group size effect on direct comparative judgments was not as strong as the group size effect on absolute peer-risk judgments. To show this, we reversed the sign of all the regression coefficients in the direct condition and compared their mean (now positive) with that of the regression coefficients in the indirect condition. The difference was statistically significant, $t(154)=4.39, p<.05$. This is consistent with the idea that people attended less to the comparison target when making direct comparative judgments than when making indirect comparative judgments.

\section{Experiment 3}

It is clear from the first two experiments that the group size effect does not depend on the specific design and procedure used by Price (2001) in his original demonstration. Because these experiments show a group size effect on online risk judgments with stimulus individuals that are not conveniently presented as lists of discrete risk factors, explanations hinging on the assumption of selective memory for high-risk features or individuals are implausible. Next, we turn our attention to explanations that do not necessarily assume selective memory for specific features or individuals. These include the affective theory, the person-positivity theory, and the numerosity theory. The manipulation that we introduce in Experiment 3 is that participants in one condition make risk judgments as in Experiments 1 and 2. Participants in two other conditions judge the likelihood that the average group member, and they themselves, will experience various positive or neutral events.

Research on comparative optimism has shown not only that people tend to judge themselves to be less likely than their peers to experience negative events but also that they judge themselves to be more likely than their peers to experience positive events (e.g., Hoorens, 1996; Weinstein, 1980). We have seen that comparative optimism for negative events increases as a function of group size. However, what will happen for positive events? There are two distinct possibilities. One is that comparative optimism for positive events will also increase as a function of group size. This requires, however, that the group size effect reverse direction so that larger groups are judged less likely to experience the events. Note that this would be consistent with the person-positivity theory of the group size effect. If larger groups are perceived to be less similar to the self and, therefore, are liked less, then larger groups should be judged to be both more likely to experience negative events, as we know that they are, and less likely to experience positive events.

The second possibility is that comparative optimism for positive events will decrease as a function of group size. This would happen if larger groups were judged to be more likely to experience positive events, just as they are judged to be more likely to experience negative events. This result would be consistent with the more general affective theory of the group size effect. According to this theory, when the event is negative, people feel more negatively about larger groups, which contain more potential victims or losers, and therefore judge the average group member to be more likely to experience the event. Generalizing to positive events, people feel more positively about a larger group, which contains more potential winners, and again judge the average group member to be more likely to experience the event. For example, people might perceive more potential award winners in a larger group, feel more positively about the group as a whole, and therefore judge the likelihood that the average group member will win an award to be greater. If this were the case, it would not be 
surprising to observe an asymmetry between the effect sizes for negative and positive events. Reviews have shown convincingly that across a wide range of situations negative affect tends to be elicited more easily and experienced more intensely than positive affect (Baumeister, Bratslavsky, Finkenauer, \& Vohs, 2001; Rozin \& Royzman, 2001). For this reason, the group size effect for negative events might be stronger than the group size effect for positive events. The important point, however, is that the personpositivity and general affective theories make directly opposing predictions about what will happen with positive events.

What about neutral events? Neither the person-positivity theory nor the general affective theory implies a group size effect for neutral events. One reason is that neutral events should not elicit either positive or negative affect, meaning there would be no affective response to grow in magnitude as a function of group size. Another is that even if larger groups tend to elicit greater negative affect regardless of the valence of the event (as in the person-positivity theory), this negative affect would probably not influence the likelihood judgment because it would be interpreted as irrelevant to it. This is because affect generally influences judgment only to the extent that it can be interpreted as being relevant to the judgment (Martin, 2000; Schwarz, 1990; Zajonc, 2000). For example, it seems reasonable to think that people might interpret negative affect as indicating that the group members they are considering are relatively likely to die early or relatively unlikely to win an award. However, what would such negative affect imply about the likelihood that they will some day own a white car or subscribe to a magazine? Our assumption is that it would imply nothing and, therefore, fail to influence those judgments.

Now consider the numerosity theory. Pelham et al. (1994) have shown quite convincingly that people use stimulus numerosity as a cue to a wide variety of quantitative judgments, and Wilson et al. (1996) have shown that people sometimes integrate an irrelevant number into their frequency judgments. Both of these results suggest that a larger group might be judged more likely to experience negative events, positive events, and neutral events. Furthermore, barring ceiling effects, the numerosity theory suggests that the group size effect should be equally strong regardless of the valence of the event.

\section{Method}

Participants. The participants were 68 undergraduate students at CSUF. They participated as part of an introductory psychology course requirement.

Design and procedure. Participants judged the likelihood that each of eight events would happen to each of 5 stimulus individuals and to the average member of three different-sized groups: 5, 10, and 15. The stimulus photographs were those used in Experiment 1, and the 5 stimulus individuals were a randomly selected subset of the entire set of 30 photographs that was varied from session to session. The individuals and groups were presented as in Experiment 1, with the individual-group order and the order of the groups counterbalanced across experimental sessions. Judgments were made on a 7-point likelihood scale like the risk scale used in the indirect condition of Experiment 2, except that the word chance was added to all the response alternatives (e.g., extremely low became extremely low chance). After making all eight likelihood judgments for a comparison target, participants judged the similarity of the target to themselves on a 6-point verbal scale ranging from extremely dissimilar to me (1) to extremely similar to me (6). Finally, after making judgments about all the individuals and groups, participants judged the likelihood that they would experience each of the eight events using the same 7-point likelihood scale they had used to make their peer-risk judgments.

All participants in each session were randomly assigned either to the negative-events $(n=20)$, positive-events $(n=18)$, or neutral-events $(n=$ 30) condition. In the negative-events condition, the eight events were as follows: becoming alcoholic, being injured in a car crash, developing cancer, having one's home burglarized, buying a car that turns out to be a lemon, having a heart attack by the age of 40 , getting fired from a job, and suffering a broken bone. In the positive-events condition, the eight events were as follows: having a long and happy marriage, getting a desirable postgraduate job, graduating in the top $25 \%$ of one's class, having an intellectually gifted child, living past the age of 80 , earning a six-figure income by the age of 30, owning a home, and having one's work recognized with an award. In the neutral-events condition, the eight events were as follows: living in a town with fewer than 50,000 people, having exactly two children, working for a relative, owning a turtle, owning a white car, traveling to Idaho, subscribing to a magazine, and painting a picture. A pilot study $(n=14)$ in which all 24 of these events were rated on a 7-point scale $(1=$ extremely negative, $2=$ somewhat negative, $3=$ slightly negative, $4=$ neutral, $5=$ slightly positive, $6=$ somewhat positive, $7=$ extremely positive) confirmed that the negative events were perceived as quite negative $(M=1.38, S D=0.44)$, the positive events were perceived as quite positive $(M=6.44, S D=0.29)$, and the neutral events were perceived as relatively neutral $(M=4.33, S D=0.30)$.

\section{Results and Discussion}

Figure 3 shows the mean likelihood judgment as a function of the logarithm of the group size separately for each event type condition. It appears that there was a positive group size effect for all three event types. Again, for each participant, we regressed the four mean likelihood judgments onto the logarithm of the group size, obtaining a regression coefficient for each participant. The overall mean regression coefficient was significantly greater than $0(M=0.26, S D=0.38), t(67)=5.52, p<.05$. A two-way analysis of variance (ANOVA) on the regression coefficients, with event type (negative, positive, and neutral) and order (groups first vs. groups last) as between-subject variables, did not reveal a statistically significant main effect of event type, $F(2,62)=0.94$,

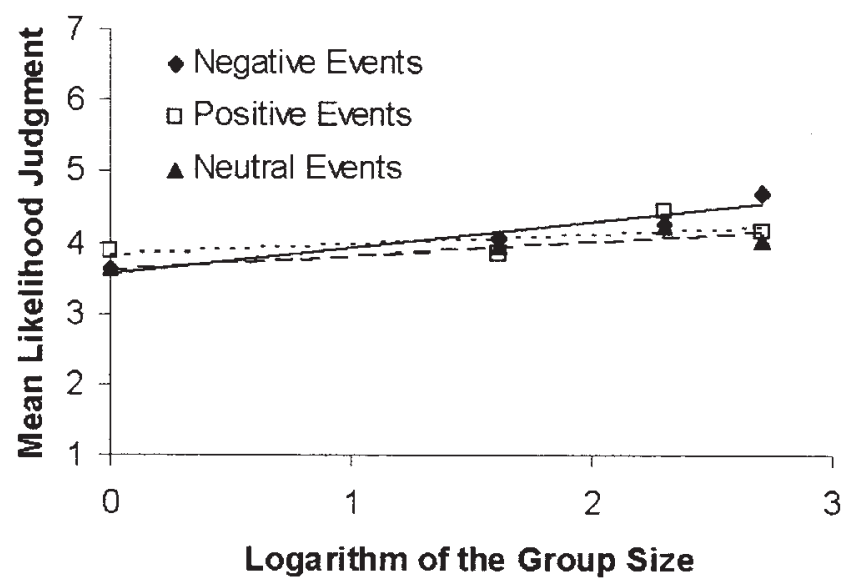

Figure 3. Mean peer-likelihood judgments as a function of the logarithm of the group size for Experiment 3 for negative, positive, and neutral events. The stimuli were photographs of real peers. The likelihood judgments were made on a 7-point verbal scale. 
$n s$. This entire pattern of significant and nonsignificant results was replicated when the analysis excluded individual peer-risk judgments. Taken together, these results seem inconsistent with the person-positivity theory of the group size effect, because that explanation predicts a reverse group size effect for positive events and no group size effect for negative events. They also seem inconsistent with the affective theory, because, although it predicts a group size effect for positive events, it predicts no group size effect for neutral events. These results are consistent, however, with the numerosity theory.

The ANOVA described previously also failed to reveal a statistically significant effect of judgment order, $F(1,62)=0.08$, ns. Thus, unlike in Experiment 1, the group size effect was roughly the same regardless of whether participants made judgments about the groups before making judgments about the individuals or vice versa. It seems plausible that this has to do with the relatively small number of individual peer judgments that they made. In Experiment 1 , there were 30 stimulus individuals, the same individuals who made up the groups of 5, 10, and 15. For this reason, participants in the groups-last condition, which showed no group size effect, always made judgments about groups whose individual members they had already seen and made judgments about. Again, this might have encouraged them to make their group judgments by recalling and averaging the individual peer judgments that they had already made. In the present experiment, however, only 5 stimulus individuals were a small subset of the group members. For this reason, participants in the groups-last condition in this experiment, which did show a group size effect, made judgments about groups whose individual members they mostly had not seen before. This might have discouraged them from recalling and averaging their previous individual peer judgments and encouraged them to make more holistic group-risk judgments.

An especially interesting pattern of results emerges when we consider how comparative optimism - the difference between peer-risk and self-risk judgments - changes as a function of group size. Not surprisingly, participants judged negative events to be less likely to happen to themselves $(M=2.68, S D=0.76)$ than to other individuals, $t(19)=7.66, p<.05$. This means that, again, participants were comparatively optimistic even when comparing themselves with individual peers, and that they became more comparatively optimistic as the size of the comparison group increased. Also not surprisingly, given previous research on comparative optimism for positive events, participants judged positive events to be more likely to happen to themselves $(M=4.79, S D=$ $0.75)$ than to other individuals, $t(17)=3.65, p<.05$, although this effect was weaker than the effect for negative events. However, because they judged larger groups to be more likely to experience positive events, the degree to which participants were comparatively optimistic actually decreased as the size of the comparison group increased. Their peer judgments for the group of 15 were still significantly lower than their self-judgments, $t(17)=2.55$, $p<.05$. These results suggest that group size effect is likely an important reason why comparative optimism for positive events is weaker and less reliable than for negative events (Hoorens, 1996; Weinstein, 1980). People judge themselves to be more likely than individual peers to experience positive events, but the effect of increasing the size of the comparison group actually works to counteract this comparative optimism by making their peers seem more likely to experience the positive events.
With neutral events, participants' self-judgments $(M=3.43$, $S D=0.94$ ) were not statistically significantly different from their individual peer judgments, $t(19)=1.12, n s$. This lends additional support to our assumption that the neutral events were indeed neutral. However, because again their peer judgments increased as a function of comparison group size, participants judged the average member of a group of 15 to be significantly more likely than themselves to experience the neutral events, $t(29)=4.40, p<.05$. This is a particularly interesting result because it cannot sensibly be called comparative optimism or comparative pessimism. Instead, it appears to be an entirely nonmotivated effect of the size of the comparison group. It is the group size effect in its purest form.

Figure 4 presents the mean similarity judgment as a function of the logarithm of the group size separately for each event type. Although not highly pertinent to our major concerns, there appears to have been a main effect of event type on the similarity judgments, with participants judging the comparison target to be relatively similar to themselves in the positive condition and relatively dissimilar to themselves in the negative condition. A repeated measures ANOVA, with group size as the within-subjects factor and both event type and judgment order as between-subjects factors, confirmed that there was a statistically significant effect of event type, $F(2,62)=3.35, p<.05$. This is not an effect of the comparison targets themselves, which were exactly the same across the three event-type conditions but an effect of the judgments that participants made. Compared with thinking about neutral events, thinking about the possibility of good things happening to the comparison target increased the perceived similarity of the target to the self. Thinking about the possibility of bad things happening to the comparison target decreased the perceived similarity of the target to the self.

Turning to the effect of group size, the first thing to notice is that if there is a trend in the data, it is toward greater perceived similarity of the groups to the self than other individuals to the self. This is in direct opposition to the usual theoretical assumptions behind the person-positivity bias (e.g., Miller \& Felicio, 1990; Sears, 1983), adding to the evidence against it as an explanation of the group size effect. This result could be interpreted, however, as

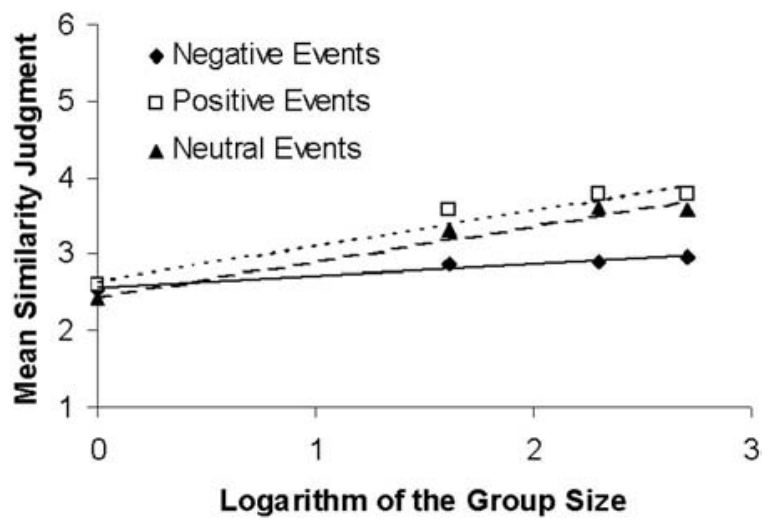

Figure 4. Mean similarity judgments as a function of the logarithm of the group size for Experiment 3 for negative, positive, and neutral events. The stimuli were photographs of real peers. The similarity judgments were made on a 6-point verbal scale. 
a group size effect on the similarity judgments. For consistency, we tested for such an effect using the same regression procedure we used for the likelihood judgments. The overall mean regression coefficient was greater than $0(M=0.06, S D=0.10), t(67)=$ 5.38, $p<.05$, and an ANOVA revealed no effects of either event type, $F(2,62)=2.06, n s$, or judgment order, $F(1,62)=0.36, n s$ Although these results suggest a group size effect on participants' similarity judgments, we found that when we eliminated the individual peer judgments from the analysis, the effect became much smaller and nonsignificant. The overall mean regression coefficient $(M=0.02, S D=0.14)$ was not significantly greater than 0 , $t(67)=1.25, p=.21$. This suggests that, rather than a group size effect, the effect on similarity judgments might be an effect of the comparison target's being an individual versus a group regardless of the group size. For example, participants might have been more likely to categorize groups than individuals as "young adults" or "college students," categories to which the participants themselves belonged, thus enhancing the perceived similarity of the average group member to themselves.

\section{Experiment 4}

The available evidence seems most consistent with the numerosity theory of the group size effect. That is, it seems most consistent with the idea that people's judgments are influenced in a fairly direct way by the total number of stimulus individuals. However, although we have ruled out selective memory for highrisk individuals and high-risk features - the judgments in Experiments 1 through 3 were not memory based-we have not ruled out the possibility of selective attention to high-risk individuals and high-risk features. In other words, instead of integrating the total number of stimulus individuals with their judgments, people might be integrating the number of high-risk individuals or high-risk features with their judgments. In Experiments 4 and 5, we pit the numerosity theory against these two alternatives.

The numerosity theory clearly implies that the group size effect should not depend on variability among the individuals in terms of their perceived risk. The high-risk individual interpretation, by contrast, requires that some of the individuals be perceived at higher risk than others so that judgments can be influenced specifically by the number of high-risk individuals. Another implication of the numerosity theory is that the group size effect should not depend on the individuals having any discernible features. The high-risk feature theory, by contrast, requires that the individuals have discernible features so that judgments can be influenced specifically by the number of high-risk features. Thus, if the stimulus individuals were, for example, identical stick figures with no discernible risk-relevant features, the numerosity theory predicts that there should still be a group size effect. People should still integrate the total number of stick figures with their risk judgments. This is why in Experiment 4 the stimulus individuals were identical stick figures.

\section{Method}

Participants. The participants were 40 undergraduate students at CSUF. They participated as part of an introductory psychology course requirement.

Design and procedure. We created 16 stimulus displays, 4 each containing 1, 5, 10, and 15 stick figures. Above each display were instructions stating that the stick figures represented randomly selected CSUF students along with a question asking for a judgment of the risk that the typical student in the group would experience one of four negative events: developing heart disease, being hurt in a car crash, dropping out of college, or being fired from a job. Each group size was paired once with each negative event to produce the 16 different displays. We also varied the major department from which the students were said to have been drawn: psychology, chemistry, math, or sociology. We included this variable only to disguise our true hypothesis, so we did not combine it factorially with the other independent variables. Instead, we created two different sets of stimulus displays in which the major departments were paired with the group sizes and the events in different ways. We then combined the 16 displays into a questionnaire with one display per page. Each page also included a numerical risk scale ranging from 1 (extremely low risk) to 9 (extremely high risk). The order of the displays was randomized separately for each participant.

Participants were tested in noninteracting groups of approximately 10. Each participant was given a questionnaire that began with a set of instructions explaining the task. They then completed the questionnaire at their own pace, circling the number on the rating scale that corresponded to their risk judgment for each stimulus display.

\section{Results and Discussion}

For each participant, we computed the mean risk judgment across events for the groups of $1,5,10$, and 15 . The means of these four mean risk judgments are shown in Figure 5 as a function of the logarithm of the group size. Again, there appears to have been a roughly logarithmic group size effect. For each participant, we obtained a regression coefficient by regressing the four mean risk judgments onto the logarithm of the group size. The mean of these regression coefficients was $0.36(S D=0.71)$, which is significantly greater than $0, t(39)=3.20, p<.05$. Again, this group size effect remained even when displays containing individual stick figures were eliminated from the analysis. Although this result seems inconsistent with both the idea of selective attention to high-risk individuals and high-risk features, it is entirely consistent with the numerosity theory.

\section{Experiment 5}

As we have presented it, the numerosity theory is quite general. There is no reason that the judgment has to be about risk or

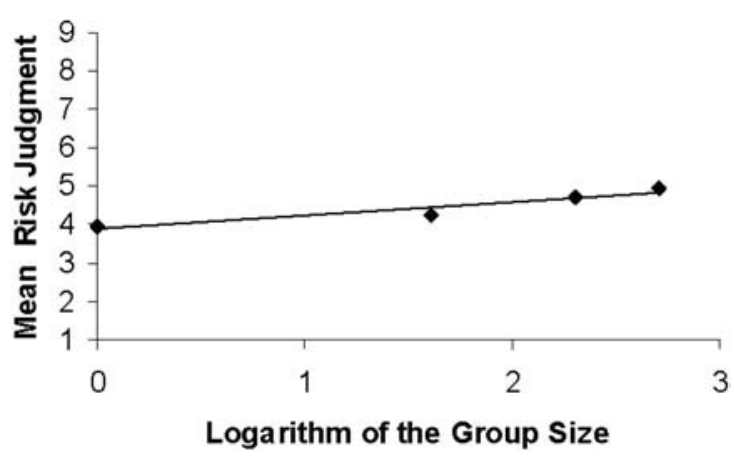

Figure 5. Mean peer-risk judgments as a function of the logarithm of the group size for Experiment 4. The stimuli were stick figures said to represent randomly selected peers. The risk judgments were made on a 9-point numerical scale. 
likelihood; it could be about almost any quantity. This follows from research on both the numerosity heuristic (Pelham et al., 1994) and basic anchoring (Wilson et al., 1996). In the former, stimulus numerosity has been shown to affect a variety of conceptual, perceptual, and social judgments (Pelham et al., 1994). In the latter, an irrelevant number presented before participants make frequency judgments has been shown to be integrated into those frequency judgments. Furthermore, research on basic anchoring in particular suggests that the effect is unconscious, automatic, and not easily debiased.

To explore the generality of the group size effect, therefore, we presented participants with sets of stick figures, much as in Experiment 4 . However, the quantity to be judged was not the likelihood of experiencing a negative event, which is an abstract quantity that must be inferred. Instead, it was the height of the stick figures themselves, a concrete quantity that is perceived directly. Nevertheless, according to the numerosity theory, the judged height of the average stick figure should increase as a function of the number of stick figures in the stimulus display. Again, this is because the numerosity theory is that people automatically integrate the number of distinct stimulus elements with their quantitative judgments about that stimulus. In this case, they integrate the number of stick figures with their judgments of the average height of the stick figures.

The switch from risk and likelihood judgments to height judgments also allows us to test two alternative interpretations of the group size effect. One is that as the group size increases, it becomes increasingly easy for people to imagine the negative event happening to one or more individuals in the group. If a person thinks that the base rate of being injured in a car crash is $25 \%$, then he or she might assume that it is unlikely to happen to any particular individual, or even to the typical member of a group of two or three, because it is difficult to conceptualize $25 \%$ of such a small group. The person might also assume that being hurt in a car crash is more likely to happen to the typical member of a larger group because it is easier to conceptualize $25 \%$ of that group (e.g., one person out of four). With height judgments, however, there is no need to conceptualize any fraction of the group. Every individual has some height that can be perceived directly, and these heights simply need to be averaged across all group members regardless of whether the group is small or large. A group size effect on height judgments, therefore, would rule out this alternative interpretation.

A second alternative interpretation is that participants in our studies are simply misunderstanding their task. They interpret our instruction to judge the risk of the average person in the group to mean that they are to judge the risk that the event will happen to at least one person in the group, a quantity that does increase as a function of group size. However, there is no equivalent misunderstanding for height judgments. The only remote possibilities would be to mistakenly judge the likelihood that at least one group member is tall or to mistakenly judge the height of the tallest group member. Given that participants are asked specifically to judge the height of the average group member, however, both of these misunderstandings seem highly implausible.

\section{Method}

Participants. The participants were 55 introductory psychology students at CSUF. They participated in partial fulfillment of a course requirement.
Design and procedure. We created 18 different stimulus displays, each consisting of $1,4,8$, or 12 stick figures. The 18 displays included four distinct subsets. Each of the first two subsets consisted of four displays of $1,4,8$, and 12 stick figures. In Subset A all the stick figures were $4.52 \mathrm{~cm}$ tall and in Subset B they were all $4.90 \mathrm{~cm}$ tall. We refer to these as the nonvariable subsets because all the stick figures within each subset were the same height. Each of the second two subsets consisted of five displays: two had 1 stick figure and the other three had 4,8 , or 12 stick figures. In Subset C, half the stick figures were $4.09 \mathrm{~cm}$ tall and half were $4.95 \mathrm{~cm}$ tall, so that their mean height equaled the height of the stick figures in Subset A. In Subset D half the stick figures were $4.47 \mathrm{~cm}$ tall and half were 5.33 $\mathrm{cm}$ tall so that their mean height equaled the height of stick figures in Subset B. We refer to these as the variable sets because the heights of the stick figures varied within them. In the upper left corner of each display was a legend with a vertical line $0.84 \mathrm{~cm}$ long that was said to represent 1 $\mathrm{ft}$. This vertical line was used by participants as a standard for judging the heights of the stick figures in feet and inches. We photocopied the 18 stimulus displays onto overhead transparencies for presentation much as in Experiments 1 through 3.

Participants were tested in noninteracting groups of approximately 5 to 10 in a classroom on the university campus. They were informed that they would be judging the height of the average stick figure in each of several displays in feet and inches. They were presented with two sample displays to introduce them to the task and the use of the standard for making their judgments. One sample display was similar to those that they would make judgments about, and the other showed an array of six stick figures that, according to the standard, ranged in height from 6 feet 6 in. to $4 \mathrm{ft}$. Half the participants then saw the 18 displays in a fixed order, in which displays from Sets A through D and with group sizes of 1 through 12 were thoroughly mixed. The rest saw the 18 displays in the reverse order. For each display, participants wrote their judgments on a separate response sheet in feet and inches.

\section{Results}

One participant was dropped from the analyses for giving responses that were difficult to interpret in the context of the task, so the following analyses are based on the responses of 54 participants. We began by converting all the height judgments from feet and inches to inches (e.g., 5 feet, 4 in. $=64$ in.). Then, for each participant, we computed the mean height judgment across the six individual stick figures and across the groups of 4, 8, and 12 . Figure 6 presents the means of these four mean height judgments

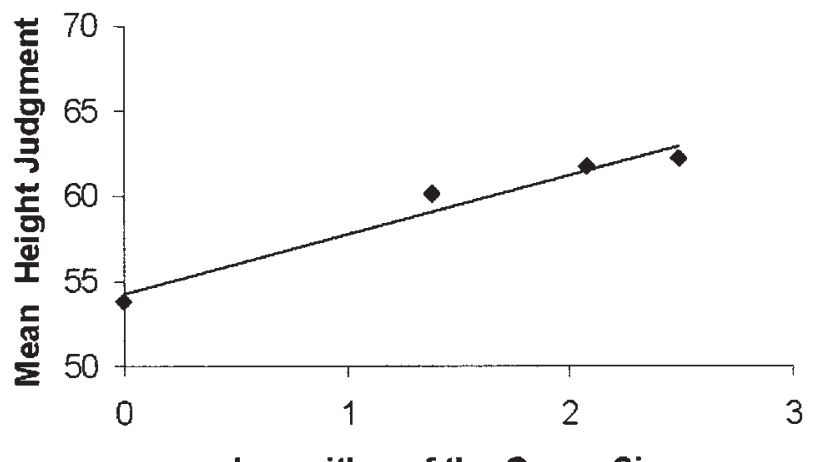

\section{Logarithm of the Group Size}

Figure 6. Mean height judgments as a function of the logarithm of the group size for Experiment 5. The stimuli were stick figures. The height judgments were made in feet and inches (converted to inches) relative to a standard line said to represent $1 \mathrm{ft}$. 
as a function of the logarithm of the group size and shows a clear group size effect. (Again, the standard deviations are presented in Table 1.) As always, we regressed the four mean judgments onto the logarithm of the group size, obtaining a regression coefficient for each participant. The mean regression coefficient $(M=3.49$, $S D=2.67$ ) was significantly greater than $0, t(53)=9.58, p<.05$, and this effect remained even when the height judgments for the individuals were excluded from the analysis.

Another interesting question is whether the group size effect is observed when the analysis is limited to the nonvariable stimulus sets. If so, this would indicate that the effect does not depend on people attending to particularly tall individuals. In fact, this appears to be the case. When the analysis was limited to the nonvariable stimulus sets, the mean regression coefficient $(M=3.65$, $S D=2.97$ ) was greater than 0 by about the same degree as for all the stimulus sets, $t(53)=9.03, p<.05$. This argues against explanations that rely on selective attention to extreme features or individuals. Instead, what seems to be driving the group size effect is the sheer number of individuals in the display.

\section{General Discussion}

We now return to the three major goals of the present research: generalizing the group size effect, showing that it affects comparative optimism, and making some theoretical headway. Ultimately, we consider the implications of the group size effect for social judgment more generally.

\section{Generalizing the Group Size Effect}

The experiments presented here show very clearly that risk judgments about the average member of a group increase as a function of the number of individuals in the group and that this group size effect is observed under a wide variety of conditions. The group size effect occurs for many different negative events but also for positive and neutral events. It occurs whether the stimulus individuals are written descriptions (Price, 2001) or, as shown here, photographs of real peers or stick-figure representations of peers. It also occurs for both absolute peer-risk judgments and for direct comparative judgments of one's own risk relative to that of the average group member. There is evidence that the group size effect generalizes beyond risk and likelihood judgments even to perceptually based height judgments. Furthermore, the function relating group size to judged risk tends to be negatively accelerated and reasonably well approximated by a logarithmic curve. The only notable exception to this pattern was that participants who made a long series of risk judgments about individual peers before making risk judgments about the average member of different size groups did not show a group size effect in Experiment $1 .{ }^{4} \mathrm{We}$ suspect that this is because these participants used an alternative strategy to make their group-risk judgments, recalling and mentally averaging the individual-risk judgments they had already made.

\section{The Group Size Effect and Comparative Optimism}

In the present experiments, the degree of comparative optimism was quite clearly affected by comparison group size. Given the apparent generality of the group size effect, we suggest that it is plausible that the typical comparative optimism effect reported in the literature is also in part a group size effect. We do so, however, with a few caveats.

First, this conclusion seems stronger when applied to comparative optimism measured using the indirect method than using the direct method. Most of the experiments here used the indirect method, in part because a group size effect is clearly predicted for this method. As the size of the comparison group increases, absolute risk judgments about the average member of that comparison group should increase, whereas absolute risk judgments about the self should remain constant (because the self is always a group of one). However, the one experiment here that used the direct method also showed a group size effect, although this effect was weaker than the experiments that used the indirect method. Given that many researchers have proposed that direct comparative judgments are essentially absolute self-judgments (Eiser et al., 2001; Klar \& Giladi, 1997, 1999; Kruger, 1999; Price et al., 2002), further research is warranted to establish a group size effect on direct comparative risk judgments. If people consistently show a group size effect, then this suggests that they must be attending to at least one feature of the comparison group.

Second, in the typical comparative optimism study, the comparison group is simply defined verbally. For example, participants might be asked to judge the risk of "the average student at your university" (e.g., Price et al., 2002; Weinstein, 1980). In the present experiments, the comparison groups consisted of photographs of actual peers in which the numerosity of the group was highly salient. Although the comparison groups in the research of Price (2001) consisted of written descriptions of individuals as opposed to photographs, numerosity was still relatively salient because the individuals were described one at a time. It is possible, therefore, that the group size effect contributes to comparative optimism only when the numerosity of the comparison group is highly salient. This is related to the first caveat. It is possible that direct comparative risk judgments showed a group size effect here only because the comparison groups were so salient. If they were less salient, then perhaps people would ignore them and make comparative risk judgments that were, in essence, absolute selfrisk judgments.

The third caveat is related to the first two but is more general. It is important to emphasize that the group size effect is an effect on peer-risk judgments, not on self-risk judgments (again, because such judgments are always about a group of one). So the increase in comparative optimism observed here is due entirely to an increase in peer-risk judgments, not a decrease in self-risk judgments. One could argue, therefore, that the present results have few or no implications for understanding risk-taking behavior. After all, people's willingness to engage in a risky behavior should not

\footnotetext{
${ }^{4}$ Another exception is that a pilot study failed to reveal a group size effect on grade point average (GPA) judgments with photographic stimuli. This same pilot study, however, did reveal a statistically significant group size effect on height judgments and weight judgments and a nonsignificant trend toward a group size effect on weekly income judgments. Given that the GPA results represent one of very few failures to replicate the group size effect, it might just represent sampling error. An alternative explanation is that it reflects a fairly obvious boundary condition of the group size effect: People's judgments will not be influenced by group size when they already have well-formed beliefs about the quantity in question.
} 
depend on judgments of their peers' risk but on judgments of their own risk. However, there is evidence that the perception of others' risk can have an effect on how people interpret their own risk. Specifically, Klein (1997) found that people reported that they would be more disturbed to learn that they had a genetic marker for a pancreatic disease when their chances of developing the disease were a higher-than-average $30 \%$ than when their chances were a lower-than-average $60 \%$ (see also Windschitl, Martin, \& Flugstad, 2002 , for a closely related result). Thus, if group size influences the perception of others' risk, then it might also influence the extent to which people are concerned about their own risk and perhaps their likelihood of taking protective action.

\section{Explaining the Group Size Effect}

The present results rule out many potential explanations of the group size effect. They argue against the person-positivity and affective theories of the group size effect. Because the personpositivity theory assumes that the average member of a larger group is perceived as less similar to the self than the average member of a smaller group and, therefore, is liked less, it implies a reverse group size effect for positive events. The average member of a larger group should be judged to be less likely to experience positive events. The person-positivity theory also implies no group size effect for neutral events because how much one likes a target should be irrelevant to such nonevaluative judgments. Yet both of these predictions were disconfirmed in Experiment 3, which also showed that people judged themselves to be more similar to the average member of a group than to other individuals, not less as predicted by the person-positivity theory. The affective theory predicts a group size effect for both negative and positive events but not for neutral events. However, we observed an effect for neutral events in Experiment 3 of roughly the same magnitude as for negative and positive events. In addition, neither of these theories predicts the group size effect on judgments of the heights of stick figures observed in Experiment 5.

The present results also argue against most of the cognitive theories considered here. It is clear that any model that relies on selective memory cannot work because the group size effect is observed for online risk judgments. It also seems clear that any model that relies on selective attention to high-risk individuals or high-risk features cannot work because of the results of Experiments 4 and 5 . In both of these experiments, the stimuli were stick figures. They had no discernible features, and there were no particularly high-risk individuals in Experiment 4 or particularly tall individuals in the nonvariable conditions of Experiment 5. Experiment 5 also argues against the idea that people make higher risk judgments for larger groups because they are better able to imagine the negative event happening to at least one individual as the group size increases, and it argues against the idea that participants misunderstand their task as that of judging the risk that the event will happen to at least one individual in the group. Neither of these interpretations is consistent with the effect on height judgments in Experiment 5.

The best explanation of the group size effect is the numerosity theory. The group size effect is the result of a simple, general cognitive mechanism that integrates stimulus numerosity with quantitative judgments about that stimulus. This is the only theory that predicted all the major results here. What precisely is the mechanism underlying the numerosity theory, and how does it operate? Recall that one possibility is that it is another example of people using a numerosity heuristic (Pelham et al., 1994). That is, they are overapplying the generally useful principle that stimulus numerosity is positively correlated with other quantitative dimensions of that stimulus. Although this might be a good functional description of the group size effect, we think it necessary to consider in more detail the cognitive processes that underlie it. Here we sketch our own proposal, which draws on two lines of research: (a) research on the representation and processing of numerosity and event frequency and (b) research on basic anchoring.

First, we assume that the processing of stimulus numerosity occurs fairly automatically, without counting, and results in a modality-independent representation. The first part of this assumption is consistent with research on the representation of numerosity in infants and nonhuman animals, who reliably distinguish between collections of objects and events with different numerosities (e.g., 6 vs. 12; see Feigenson, Dehaene, \& Spelke, 2004, for a review). It is also consistent with research showing that the processing of event frequency information is automatic (e.g., Hasher $\&$ Zacks, 1979). The second part is consistent with research in which adults make cross-modal comparisons between the numerosity of, for example, a spatial array of dots and a temporal sequence of tones. Such cross-modal comparisons are essentially as accurate as comparisons made within the same sense modality, suggesting that they rely on modality-independent representations of numerosity (Barth, Kanwisher, \& Spelke, 2003). This is a particularly important point if a single theory is to account for the present results and the results of Price (2001), in which group members were distributed across time rather than space. We also assume, given the form of the group size effect, that the representation of numerosity is based on a negatively accelerated psychophysical function. This assumption is consistent with considerable research on the psychophysics of numerosity and temporal frequency perception (e.g., Feigenson et al., 2004; Hintzman, 1988; Krueger, 1982; van Oeffelen \& Vos, 1982). Thus, when people make judgments about the average or typical group member, they have an active representation of the group size, and this representation is a negatively accelerated function of the actual group size.

How and why is group size information integrated into judgments about the typical or average individual? Again, we believe that the literature on basic anchoring, in which people's quantitative judgments are biased by an irrelevant number presented beforehand, suggests an answer. Wilson et al. (1996) proposed that such effects might be the result of numeric priming. A representation of the anchor value becomes activated and integrated with the subsequent judgment. They liken this process to other wellknown priming effects on social judgment, in which, for example, judgments of a person are assimilated to an arbitrary trait category that has been activated (e.g., Higgins, 1996). It is true that basic anchoring effects can be difficult to obtain when the anchor value is completely without meaning for participants and is processed at a minimal level (Brewer \& Chapman, 2002). However, in the group size effect paradigm, the anchor value (i.e., the group size) is probably processed automatically, is meaningful (even if irrelevant for the judgment at hand), and is a property of the stimulus itself (as opposed to a completely unrelated number). All of these factors might contribute to people having an active and phenom- 
enologically relevant representation of group size that they integrate into their judgments about the average or typical group member.

Given these theoretical assumptions, it is worth asking whether there are conditions under which we would not expect a group size effect. There are some obvious possibilities. One is that there may be situations in which the group size is not salient enough to produce an active representation. As suggested previously, this might be the case when the group size is merely implied. For example, asking participants to judge the risk of the average student in an introductory psychology lecture (a large group) versus a discussion or recitation section (a much smaller group) might not produce a group size effect because participants might not bother to think about the group size. Also, consistent with other research on conceptual and affective priming (e.g., Higgins, 1996; Martin, 2000; Schwarz, 1990), there might be no group size effect when participants can attribute their intuitive sense of numerosity to its actual source. For example, merely counting the group members might be enough to allow participants to attribute their intuitive sense of numerosity to the size of the group. This, in turn, might prevent them from integrating this intuitive sense of numerosity into their judgment.

A final theoretical point is that our focus has been on explaining the group size effect on risk judgments. Our claim that affective processes do not underlie the group size effect should not be taken as a claim that they do not underlie risk judgments in general. In fact, the latter claim would clearly run counter to the wellsupported "affect heuristic" (Slovic et al., 2002) and "risk as feelings" (Loewenstein et al., 2001) perspectives on risk perception. The same goes for the other kinds of explanations that we have considered. Our doubts that attention to specific features of the stimulus individuals or attention to specific individuals underlies the group size effect are not doubts that these processes underlie risk judgments in general. When making risk judgments about individuals, our participants did not make the same judgment for all of them. They clearly made distinctions based on their sex, style of dress, and other personal characteristics (see also Price, 2001). Although it remains to be determined what other cues people are using when they judge the likelihood that the average person in a group will someday own a turtle, it seems clear that they are using group size.

\section{Implications for Social Judgment}

Although we have established the group size effect most clearly in the domain of risk judgment, there is good reason to believe that it should be observed in other areas of social judgment. First, there is the fact that there was a group size effect on likelihood judgments for positive and neutral events in Experiment 3 and a group size effect on height judgments in Experiment 5. Second, previous research has shown what are essentially group size effects on a variety of conceptual, perceptual, and social judgments (Pelham et al., 1994; see also Wilson et al., 1996). A general hypothesis for future research, then, is that the average or typical member of a larger group is judged to have more of whatever quantity is under consideration, especially when the judgment is made quickly and intuitively, and no other more rational strategy is readily available (as in the groups-last condition of Experiment 1). The average member of a larger group might be judged friendlier, sneakier, more intelligent, and more neurotic than the average member of a smaller group.

A particularly interesting question arises when the quantity in question can be defined such that either end of the scale is the positive end. For example, it is easy to think about people in terms of how honest they are, but it is also easy to think of them in terms of how dishonest they are. Would the average member of a larger group be judged both more honest and more dishonest than the average member of a smaller group? There is a precedent for this kind of effect. Downs and Shafir (1999) found that people about whom we have more information (i.e., famous celebrities) are judged to be both more honest and more dishonest than people about whom we have less information (i.e., less famous celebrities). Their explanation for this effect, however, relies on selective memory for characteristics or behaviors that are consistent with a judgment toward the positive end of the scale. When we have more information about a target person, we recall both more honest characteristics and behaviors and more dishonest ones. Note that this explanation is actually similar to the high-risk feature frequency and high-risk individual frequency models presented earlier. If the group size effect can be shown to follow this pattern, with the average member of larger groups being judged both more honest and more dishonest, it would be important to consider more carefully the parallels between the group size effect and the effect reported by Downs and Shafir.

\section{Other Perspectives on Differences Between Judgments About Individuals and Groups}

People reason differently about specific versus general cases in a variety of contexts (Sherman \& McConnell, 1996), and differences between judgments about individuals and groups have been given special attention by social psychologists. Here we consider the relationship of our group size perspective on this issue to some other prominent perspectives. As will become clear, we see these not as competing explanations of our results but rather complementary perspectives that can lead to a deeper understanding of social judgment phenomena.

Person-positivity bias. One alternative perspective is based on the person-positivity bias. Again, the fundamental assumptions of this perspective are that (a) we tend to evaluate individuals more favorably than groups because (b) we perceive them to be more similar to ourselves and therefore (c) like them more. Although we have already seen that this is not a viable explanation of the group size effect, this does not mean that the person-positivity bias perspective is not still valid and useful more generally.

The first reason is that the person-positivity bias, as originally conceptualized by Sears (1983), is not only about individual-group discrepancies. He did propose that individuals are evaluated more positively than groups but also that individuals are evaluated more positively than their individual elements (e.g., personality traits) and more positively than other objects associated with them (e.g., college courses they have taught). So the group size perspective comes into conflict with only one part of Sears's overall conception. The second reason is that there is nothing to indicate that the person-positivity bias could not coexist with the group size effect. For example, a teacher might evaluate individual students positively in part because he likes them (regardless of whether he perceives them as similar to himself). When he evaluates the class 
as a whole, however, this may not happen. At the same time, his evaluation of the class as a whole might be given a boost because of the sheer number of students. Depending on the specifics of the situation, these two effects might work together to produce an especially large difference between judgments about individuals and groups, or they might counteract each other. We think it possible that our procedure might have promoted a group size effect over a person-positivity bias because participants did not know the stimulus individuals and had very little information about them. This might have minimized their liking of them. Furthermore, group size tended to be a quite salient dimension of the comparison targets, which might have encouraged participants to take it into account. If participants had known more about the stimulus targets and if the group size were less salient, it is possible the person-positivity bias would have been more pronounced than the group size effect.

Singular-target-focus theory. In an impressive series of articles, Klar, Giladi, and their colleagues (Klar, 2002; Klar \& Giladi, 1997, 1999; Klar et al., 1996) have shown that almost any individual in a group is judged to be better than the group average when the group members have a favorable standing on the dimension of judgment. For example, college students judge a randomly selected member of a small group of peers to be friendlier than the average group member (Klar, 2002). Similarly, almost any individual is judged to be worse than the group average when the group members generally have an unfavorable standing on the dimension of judgment. For example, although people judge a randomly selected person from a self-generated list of pleasant acquaintances to be more pleasant than the average list member, they judge a randomly selected person from a list of unpleasant people to be less pleasant than average (Klar, 2002). Klar et al. explain these nonselective superiority and inferiority biases with their singular-target-focus theory. They assume that people do not sufficiently take into account the comparison group when making their judgments. Instead, they focus on the individual, judging him or her to be better than average to the extent that he or she is good and worse than average to the extent that he or she is bad, according to some more general standard.

An important boundary condition of the singular-target-focus perspective is that it applies only to direct comparative judgments, a point that Klar et al. emphasize throughout their work (e.g., Klar, 2002). The reason is that indirect comparative judgments require a separate judgment about a comparison group, making it impossible to ignore it. When asked to judge how friendly Frances is relative to a group of college students, I might be able to focus on Frances's friendliness and ignore her peers, therefore judging her to be friendlier than average. However, when asked to make separate judgments about Frances and her peers, I am forced to consider the fact that, yes, Frances is friendly, but her peers are friendly too. For this reason, the singular-target-focus theory is silent on the relationship between comparative judgments about individuals and groups when those judgments are made using the indirect method.

The simplest integration of the singular-target-focus perspective and our group size perspective, therefore, is that the former applies to direct comparative judgments and the latter to indirect comparative judgments. Of course, this is too simple. One reason is that, as we saw in Experiment 3, comparison group size can influence direct comparative risk judgments, although perhaps not to the same extent as it influences absolute peer-risk judgments. Thus, at least under some conditions, people's direct comparative judgments are sensitive to comparison group size. A second reason is that the category of direct comparative judgments could include judgments about a small group relative to a larger one. For example, a teacher might judge the quality of her current class of students relative to all the students she has taught. Although she might be relatively more focused on her current class than on her past students, we would also expect her to be influenced by the size of her current class. Like the person-positivity perspective, then, we believe that there is no reason that the singular-target-focus and group size perspectives cannot peacefully coexist.

Stereotypes. A third, and even broader, perspective on differences between judgments about individuals and judgments about groups comes from a long tradition of research on stereotypes. The consensus of this research is that people can have stereotypes about social groups, which they do not necessarily apply to individual group members (e.g., Fiske \& Neuberg, 1990; Kunda \& Spencer, 2003). This might result, for example, in our believing that college students are heavy drinkers even though we would not judge any particular college student of our acquaintance to be a heavy drinker. Likewise, we might judge the average college student to be at relatively high risk of becoming an alcoholic, but we might not judge any particular college student to be at high risk.

We should consider briefly whether this basic idea might explain the group size effect. Certainly, our stimulus individuals belonged to social groups for which people have stereotypes (e.g., college students, young adults). Furthermore, it is possible that these stereotypes were increasingly likely to be activated, or participants were increasingly likely to apply them (or weight them more heavily), as the group size increased. For example, an individual college student might be unlikely to activate our stereotype of college students, so we would not judge him or her to be at particularly high risk for becoming alcoholic. A group of three or five college students, however, might be somewhat more likely to activate our stereotype, so we would judge them to be at somewhat higher risk. The main argument against this explanation is that to produce the pattern of results observed here, the activated stereotype would have to include the belief that group members are at elevated risk for a wide variety of negative events. It does not seem plausible that the stereotype of college students includes the belief that they are at an elevated risk for developing cancer or getting divorced, for example. Although many of the positive events we used in Experiment 4 might be part of the college student stereotype (e.g., earning a high income), the neutral events seem unlikely to be (e.g., owning a turtle). It is also worth noting that in the research of Price (2001) the stimulus individuals were described only by lists of risk factors for heart disease, and they did not clearly belong to any particular stereotyped group.

As with the person-positivity and singular-target-focus perspectives, however, we believe there is no inherent conflict between the stereotype perspective and the group size perspective, although there may be some interesting points of contact. Consider the question of whether group size does, in fact, affect whether a group stereotype is activated and applied. If so, then this would enhance the group size effect when the stereotype is consistent with having more of the quantity in question, as when judging the intelligence of college students. However, it would counteract the group size effect when the stereotype is consistent with having less of the 
quantity, as when judging the likelihood that college students will become construction workers. Another interesting question is whether the group size effect might contribute to the formation and maintenance of stereotypes. For example, when people think about college students' tendency to drink alcohol, they are thinking about a large target group. As a result, they may tend to think that, on average, college students are heavy drinkers, so that this becomes a part of their stereotype or perhaps reconfirms a stereotype they already have.

\section{Conclusion}

Undoubtedly, the present research raises at least as many questions as it answers. The questions that it answers, however, are important ones. Is the group size effect on risk judgments a general phenomenon? Yes. Does comparison group size contribute to comparative optimism? Yes, with the caveats noted previously. Does the group size effect generalize beyond the domain of risk judgments? Yes. At the same time, the questions that it raises have the potential to generate an abundance of new research and to provide insights into many social judgment phenomena. What are the detailed cognitive processes underlying the numerosity heuristic? What kind of social judgments are affected by group size and what kind are not? Why? When does group size contribute to self-enhancement, and when does it run counter to it? How does group size interact with other variables (e.g., liking based on person positivity) to produce differences between judgments about individuals and judgments about groups? We look forward to more answers and, of course, new questions.

\section{References}

Alicke, M. D., Klotz, M. L., Breitenbecher, D. L., Yurak, T. J., \& Vredenburg, D. S. (1995). Personal contact, individuation, and the betterthan-average effect. Journal of Personality and Social Psychology, 68, $804-825$

Barth, H., Kanwisher, N., \& Spelke, E. (2003). The construction of large number representations in adults. Cognition, 86, 201-221.

Baumeister, R. F., Bratslavsky, E., Finkenauer, C., \& Vohs, K. D. (2001). Bad is stronger than good. Review of General Psychology, 5, 323-370.

Brewer, N. T., \& Chapman, G. B. (2002). The fragile basic anchoring effect. Journal of Behavioral Decision Making, 15, 65-77.

Burger, J. M., \& Burns, L. (1988). The illusion of unique invulnerability and the use of effective contraception. Personality and Social Psychology Bulletin, 14, 264-270.

Downs, J. S., \& Shafir, E. (1999). Why some are perceived as more confident and more insecure, more reckless and more cautious, more trusting and more suspicious, than others: Enriched and impoverished options in social judgment. Psychonomic Bulletin and Review, 4, 598610.

Eiser, R. J., Pahl, S., \& Prins, Y. R. A. (2001). Optimism, pessimism, and the direction of self-other comparisons. Journal of Experimental Social Psychology, 37, 77-84.

Feigenson, L., Dehaene, S., \& Spelke, E. (2004). Core systems of number. Trends in Cognitive Science, 8, 307-314.

Fiedler, K. (1996). Explaining and simulating judgment biases as an aggregation phenomenon in probabilistic, multiple-cue environments. Psychological Review, 103, 193-214.

Finucane, M. L., Alhakami, A., Slovic, P., \& Johnson, S. M. (2000). The affect heuristic in judgments of risk and benefits. Journal of Behavioral Decision Making, 13, 1-17.

Fiske, S. T., \& Neuberg, S. L. (1990). A continuum of impression forma- tion, from category based to individuating processes: Influences of information and motivation on attention and interpretation. In M. Zanna (Ed.), Advances in experimental social psychology (Vol. 23, pp. 1-74). San Diego: Academic Press.

Harris, P., \& Middleton, W. (1994). The illusion of control and optimism about health: On being less at risk but no more in control than others. British Journal of Social Psychology, 33, 369-386.

Hasher, L., \& Zacks, R. T. (1979). Automatic and effortful processes in memory. Journal of Experimental Psychology: General, 108, 356-388.

Helweg-Larsen, M., \& Sheppard, J. A. (2001). Do moderators of the optimistic bias affect personal or target risk estimates? A review of the literature. Personality and Social Psychology Review, 5, 74-95.

Higgins, E. T. (1996). Knowledge activation: Accessibility, applicability, and salience. In E. T. Higgins \& A. Kruglanski (Eds.), Social psychology: Handbook of basic principles (pp. 133-168). New York: Guilford Press.

Hintzman, D. L. (1988). Judgments of frequency and recognition memory in a multiple-trace memory model. Psychological Review, 4, 528-551.

Hoorens, V. (1996). Self-favoring biases for positive and negative characteristics: Independent phenomena? Journal of Social and Clinical Psychology, 15, 53-67.

Hoorens, V., \& Buunk, B. P. (1993). Social comparison of health risks: Locus of control, the person-positivity bias, and unrealistic optimism. Journal of Applied Social Psychology, 23, 291-302.

Klar, Y. (2002). Way beyond compare: Nonselective superiority and inferiority biases in judging randomly assigned group members relative to their peers. Journal of Experimental Social Psychology, 38, 331-351.

Klar, Y., \& Ayal, S. (2004). Event frequency and comparative optimism: Another look at the indirect method of self-others risks. Journal of Experimental Social Psychology, 40, 805-814.

Klar, Y., \& Giladi, E. E. (1997). No one in my group can be below the group's average: A robust positivity bias in favor of anonymous peers. Journal of Personality and Social Psychology, 73, 885-901.

Klar, Y., \& Giladi, E. E. (1999). Are most people happier than their peers, or are they just happy? Personality and Social Psychology Bulletin, 25, 585-594.

Klar, Y., Medding, A., \& Sarel, D. (1996). Nonunique invulnerability: Singular versus distributional probabilities and unrealistic optimism in comparative risk judgments. Organizational Behavior and Human Decision Processes, 67, 229-245.

Klein, W. M. (1997). Objective standards are not enough: Affective, self-evaluative, and behavioral responses to social comparison information. Journal of Personality and Social Psychology, 72, 763-774.

Krueger, L. E. (1982). Single judgments of numerosity. Perception \& Psychophysics, 31, 175-182.

Kruger, J. (1999). Lake Wobegone be gone! The "below-average effect" and the egocentric nature of comparative ability judgments. Journal of Personality and Social Psychology, 77, 221-232.

Kunda, Z., \& Spencer, S. J. (2003). When do stereotypes come to mind and when do they color judgment? A goal-based theoretical framework for stereotype activation and application. Psychological Bulletin, 129, 522 544.

Loewenstein, G. F., Weber, E. U., Hsee, C. K., \& Welch, N. (2001). Risk as feelings. Psychological Bulletin, 127, 267-286.

Lorch, R. F., \& Myers, J. L. (1990). Regression analyses of repeated measures data in cognitive research. Journal of Experimental Psychology: Learning, Memory, and Cognition, 16, 149-157.

Martin, L. L. (2000). Moods do not convey information: Moods in context do. In J. P. Forgas (Ed.), Feeling and thinking: The role of affect in social cognition (pp. 153-177). New York: Cambridge University Press.

Miller, C. T., \& Felicio, D. M. (1990). Person-positivity bias: Are individuals liked better than groups? Journal of Experimental Social Psychology, 26, 408-420. 
Nilsson, I., \& Ekehammar, B. (1987). Person-positivity bias in political perception? European Journal of Social Psychology, 17, 247-252.

Otten, W., \& Van der Pligt, J. (1996). Context effects in the measurement of comparative optimism in probability judgments. Journal of Social and Clinical Psychology, 15, 80-101.

Pelham, B. W., Sumarta, T. T., \& Myaskovsky, L. (1994). The easy path from many to much: The numerosity heuristic. Cognitive Psychology, 26, 103-133.

Perloff, L. S., \& Fetzer, B. K. (1986). Self-other judgments and perceived vulnerability to victimization. Journal of Personality and Social Psychology, 50, 502-510.

Peterson, C. R., \& Beach, L. R. (1967). Man as an intuitive statistician. Psychological Bulletin, 68, 29-46.

Price, P. C. (2001). A group size effect on personal risk judgments: Implications for unrealistic optimism. Memory \& Cognition, 29, 578586

Price, P. C., Pentecost, H. C., \& Voth, R. D. (2002). Perceived event frequency and the optimistic bias: Evidence for a two-process model of personal risk judgments. Journal of Experimental Social Psychology, 38, 242-252.

Regan, P. C., Snyder, M., \& Kassin, S. M. (1995). Unrealistic optimism: Self-enhancement or person positivity? Personality and Social Psychology Bulletin, 21, 1073-1082.

Rothman, A. J., Klein, W. M., \& Weinstein, N. D. (1996). Absolute and relative biases in estimations of personal risk. Journal of Applied Social Psychology, 26, 1213-1236.

Rozin, P., \& Royzman, E. B. (2001). Negativity bias, negativity dominance, and contagion. Personality and Social Psychology Review, 5, 296-320.

Schwarz, N. (1990). Feelings as information: Informational and motivational functions of affective states. In E. T. Higgins \& R. M. Sorrentino (Eds.), Handbook of motivation and cognition: Foundations of social behavior (Vol. 2, pp. 527-561). New York: Guilford Press.

Sears, D. O. (1983). The person-positivity bias. Journal of Personality and Social Psychology, 44, 233-250.
Sherman, S. J., \& McConnell, A. R. (1996). The role of counterfactual thinking in reasoning. Applied Cognitive Psychology, 10, 113-124.

Slovic, P., Finucane, M., Peters, E., \& MacGregor, D. G. (2002). The affect heuristic. In T. Gilovich, D. W. Griffin, \& D. Kahneman (Eds.), Intuitive judgment: Heuristics and biases (pp. 397-420). New York: Cambridge University Press.

van Oeffelen, M. P., \& Vos, P. G. (1982). A probabilistic model for the discrimination of visual number. Perception \& Psychophysics, 32, $163-$ 170.

Weinstein, N. D. (1980). Unrealistic optimism about future life events. Journal of Personality and Social Psychology, 39, 806-820.

Weinstein, N. D. (1987). Unrealistic optimism about susceptibility to health problems: Conclusions from a community-wide sample. Journal of Behavioral Medicine, 10, 481-500.

Weinstein, N. D. (1989). Optimistic biases about personal risks. Science, 246, 1232-1233.

Weinstein, N. D., \& Klein, W. M. (1996). Unrealistic optimism: Present and future. Journal of Social and Clinical Psychology, 15, 1-8.

Whitley, B. E., \& Hern, A. L. (1991). Perceptions of vulnerability to pregnancy and the use of effective contraception. Personality and Social Psychology Bulletin, 17, 104-110.

Wilson, T. D., Houston, C. E., Etling, K. M., \& Brekke, N. (1996). A new look at anchoring effects: Basic anchoring and its antecedents. Journal of Experimental Psychology: General, 125, 387-402.

Windschitl, P. D., Martin, R., \& Flugstad, A. R. (2002). Context and the interpretation of likelihood information: The role of intergroup comparisons on perceived vulnerability. Journal of Personality and Social Psychology, 82, 742-755.

Zajonc, R. B. (2000). Feeling and thinking: Closing the debate over the independence of affect. In J. P. Forgas (Ed.), Feeling and thinking: The role of affect in social cognition (pp. 31-58). New York: Cambridge University Press. 